\title{
Wind Turbine Planetary Gear Defect Detection with Mathematical Modelling through Transmission Error
}

\author{
Sureshkumar.S, B. Umamaheswari, Vijayaragavan C.M
}

\begin{abstract}
Analysis and prediction of planetary gear set defects has been a requirement in the wind power sector since years. Though a wind turbine gearbox is operating with many different gear types, planetary gear stage finds use in the modern era due to its high torque-to-weight ratio. This paper aims to build and validate the mathematical model of planetary gear set and understand the change in dynamic response by changing the error function during gear meshing. A single stage planetary gear has been implemented for the purpose of verification of the mathematical model. MW sized gearbox parameters have been fed to the model and real gear defect amplitude has been taken as error in the model. This helps understanding the dynamic behaviour of planetary gear set during operation under defective gear condition.
\end{abstract}

Keywords-condition monitoring; single stage planetary gear set; wind turbine gearbox; Mathematical modelling; total harmonic distortion; Transmission error.

\section{INTRODUCTION}

Wind energy is one of the forms of renewable energy harvesting. Wind turbine industry is growing exponentially over time to meet the demand created all over the world. The most important part of the wind turbine is the drive train, which consists of a gearbox, a rotor and a generator. The gearbox is an important component which increases rotational velocity and decreases the driving torque. In a typical wind turbine planetary gearbox, the planet carrier is connected to the drive end (wind turbine blades), sun gear is connected to the generator end and planets transfer energy from the sun to the carrier. Cheng-Chi Huang et al. [1] presents the development of a Magnetic planetary gearbox in which conventional gear meshing method is replaced by magnet repulsions and attractions, But the cogging torque produced by this gearbox is very high and need more planets to avoid pole-slipping.

Dynamic model and equations for Multi-stage gear transmission system (Two-parallel shaft gear transmission system; widely used) are derived with solution resulting in a comparison of parameters like speed, damping, modulus and precision provides information about noise and vibration in multi-stage gear transmission systems [2]. Planetary gear trains establish a unique dynamic behaviour [3]. The parameters of the gear train have influence on the dynamic characteristics. Various parameters of gear train taken for

Revised Manuscript Received on October 25, 2019.

Sureshkumar.S, Research Scholar, EEE Anna University, Chennai, Indiasur135@yahoo.com

B.Umamaheswari, Professor, EEE, Anna University, Chennai, India umamahesb@annauniv.edu

Vijayaragavan C.M, Research Scholar, EEE, Anna University, Chennai, India ragavan.cmv@gmail.com analysis and characteristic are presented. One of the common nonlinearities occurring in a gear transmission joint is backlash and its influence on the performance of the gear transmission system has been elaborated in [4]. Results indicate a certain range of backlash having only very little effect on the transmission performance.

The planetary gear train which finds extensive use in the wind turbine, sustains low speed, heavy load and transient conditions. Random wind causes damage to the gearbox and introduces difficulties in maintenance. It is vital to monitor the gearbox parameters for any early failure. Tooth pitting and cracking are frequently occurring failure modes seen in the planetary gear train [5]. Comparison between the responses for defected tooth gearbox and healthy gearbox in both time and frequency domains is made. Zijun Zhang et al. [6] and Jianhua Cai et al. [7] have diagnosed the faults in terms of time and frequency domain data. Motor current signature analysis is a commonly used fault diagnosis method for drive system parts $[8,9]$. In comparison with traditional planetary gearbox signal analysis method, Park transform vector-based frequency analysis method has a good effect on the characteristic frequency extraction of a three-phase current signal. Load torque oscillations generated by planetary gearbox faults in induction motor are discussed by Z.Daneshi-Far et al. [9] . Dynamic behavior of planetary gear train finds a significant effect in the presence of a transmission error $[10,11]$. Till date transmission errors have not been used for the identification of faults in planetary gears and Jungho Park et al. [11] but have attempted to quantify the health of planetary gear using transmission errors.

\section{RESEARCH APPROACH}

In this paper, the author have taken up the analysis of a single stage planetary gearbox coupled to a dc generator ( $\mathrm{dc}$ generator is considered for simplicity in the analysis). The research approach is based on the error function which is fed as input to the mathematical model. The error function is considered as a planet gear defect in the planetary gear set.

\section{A. Planetary Gear Model}

The Planetary Gear set is an assembly of both external and internal spur gears. It has four key parts for a proper transfer of energy. The Epicyclic gearing arrangement comprises of four different element that produce a wide range of speed ratios in a compact layout. These elements are: (1) Sun gear, an externally toothed gear co-axial with the gear train; (2) Ring gear, an internally toothed gear co-axial with the gear train; (3) Planets, externally toothed gears which mesh with the sun and ring gear; 
and (4) Planet Carrier, a support structure for the planets, co-axial with the train. The name "epicyclic" is derived from the curve traced by a point on the circumference of a circle as it rolls on the circumference of a fixed circle.

Figure 1. Planetary gear set components

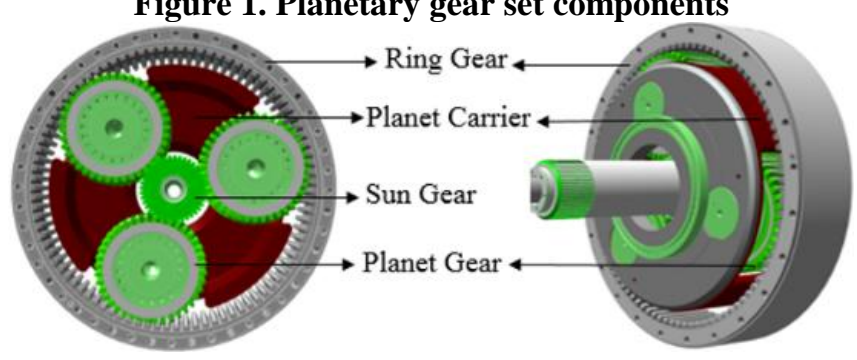

B. Composite Error Function in Dynamic Equation

The transmission error is the main contribution to the noise and vibration in the gearbox [9]. Transmission error for a planetary gearbox with three planets could be defined as equation $(1,2,3,4)$. $\mathrm{e}_{\text {spi }}(\mathrm{t})$ and $\mathrm{e}_{\mathrm{rpi}}(\mathrm{t})$ are composite errors function between sun or ring and each of the planets.

$\delta_{\text {spi }}=\theta_{g} r_{b s}-\theta_{\text {pi }} r_{b p i}-\theta_{c} r_{c} \cos \alpha-\theta_{\text {spi }}(t)$,

$\delta_{\text {rpi }}=\theta_{\text {pi }} \eta_{\text {bpi }}-\theta_{c} \gamma_{c} \cos \alpha-e_{\text {rpii }}(t)$.

$e_{\text {spi }}(t)=F_{\text {gpi }} \sin \left(\omega t+\varphi_{\text {spi }}\right)$.

$e_{\text {rpi }}(t)=F_{\text {rpi }} \sin \left(\omega t+\varphi_{\text {rpi }}\right)$

Equations (3) and (4) $e_{s p i}$, that relate to the composite error function between the meshing of the sun and the planet gear and $e_{r p i}$ represent the composite error function between planet and ring gear.

\section{SIMULATION AND ANALYSIS}

\section{A. Dynamic Model Definition}

Figure 2 shows a single stage planetary gear set, consisting of sun gear, planets attached to the carrier and a fixed ring gear. The Dynamic model consists of various dynamic parameters like damping coefficient, composite error function, inertia of solid components and Torque. The parameters indicated in model below are defined under nomenclature section in page- 1 .

Figure 2. Dynamic Model of Planetary gear set with three

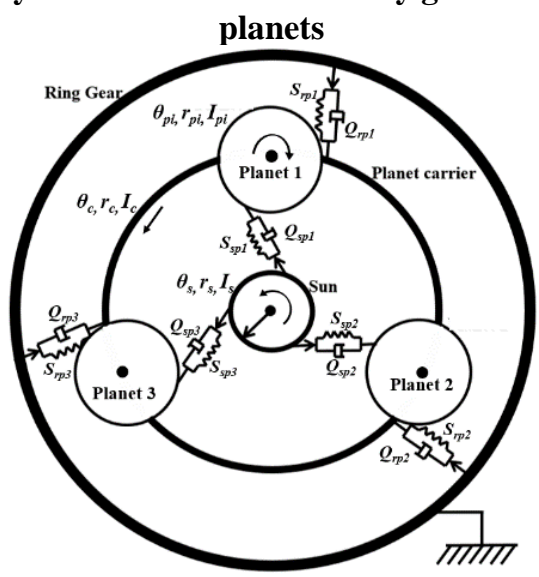

\section{B. Simulating Dynamic Equation}

The dynamic equation has been considered only for a single stage planetary gear set. Shaft and other stages are not considered for modelling and analysis. This is so with a view to simplify the model and the other components of the wind turbine gearbox like bearing.

$I_{s} \theta_{s}=T_{D}-\sum_{i=1}^{n}\left[E_{s p i}+O_{s p i}\right] \cdot r_{g}$

$I_{\text {pi }} \theta_{\text {pi }}=\left(E_{\text {spi }}+O_{\text {spi }}-E_{\text {rpi }}-O_{\text {rpii }}\right) \cdot r_{\text {pi }}$

Equation (5) is a motion equation of the sun gear, the sun gear is taken as the drive gear for the planetary gear set.

Equation (6) is the motion equation of the ith planet gear, the ith planet gear transmits the torsional energy to the carrier.

$\left(I_{c}+\sum_{i=1}^{n} m_{p i} r^{2}{ }_{c}\right) \ddot{\theta}_{c}=\sum_{i=1}^{n}\left(E_{\text {spi }}+0_{\text {spi }}+E_{\text {rpi }}+0_{r p i}\right) \cdot r_{c} \cos (\alpha)-T_{L}$

Equation (7) represents the inertia of the carrier with angular acceleration. Mass of $\operatorname{planet}\left(m_{p i}\right)$ and radius of carrier $\left(r_{c}\right)$ are equated to find the analysis of carrier.

$S(t)=S_{m}+S_{a} \sin \left(\omega t+\varphi_{0}\right)$

Equation (8) presents $S$ as the mesh stiffness function, $\omega$ as the mesh frequency and $t$ is the function of time.

$\frac{d i a}{d t}=\left(\frac{1}{L a}\right)(V-i a \cdot R a-k b d \theta s) x \quad T_{D}=k t i a_{x}$

(9)

Equation (9) is the motor equation rearranged for obtaining $d_{i a}, d_{i a}$ is the motor current, $V$ is the motor voltage, the motor is connected to the sun gear and it acts as driving force. Equation (10) presents a Developed torque $T_{D}, T_{D}$ is required and generated torque to rotate the sun gear.

$\frac{d i g}{d t}=\left(\frac{1}{L_{a}}\right)(G-i g R)$

$$
G=K b g \frac{d \theta c}{d t^{x}}
$$

Equation (11) is a generator equation rearranged for obtaining dig, dig is the generator current, $G$ is the generated voltage with planetary gear load. The generator is connected to the driven side of the planetary gear set. The driven side of planetary gear is carrier. Equation (12) presents Generator voltage $G$.

\section{Input Parameters for Motor, Planetary Gear Set and Generator}

Table 1. Input Data for Simulation

\begin{tabular}{|l|l|l|l|}
\hline \multicolumn{1}{|c|}{ Parameters } & Value & Parameters & Value \\
\hline $\begin{array}{l}\text { Mass of the Planet } \\
\text { gear, } \mathrm{M}_{\mathrm{P}}\end{array}$ & $0.66[\mathrm{~kg}]$ & $\begin{array}{l}\text { Number of sun } \\
\text { tooth }\end{array}$ & 18 \\
\hline Sun gear radius, $\mathrm{r}_{\mathrm{s}}$ & $\begin{array}{l}0.0405[\mathrm{~m} \\
]\end{array}$ & $\begin{array}{l}\text { Number of ring } \\
\text { tooth }\end{array}$ & 87 \\
\hline $\begin{array}{l}\text { Planet gear radius, } \\
\mathrm{r}_{\mathrm{p}}\end{array}$ & $0.0525[\mathrm{~m}]$ & $\begin{array}{l}\text { Number of } \\
\text { planet tooth }\end{array}$ & 34 \\
\hline $\begin{array}{l}\text { Planet carrier } \\
\text { radius, } \mathrm{r}_{\mathrm{c}}\end{array}$ & $0.0925[\mathrm{~m}]$ & $\begin{array}{l}\text { Generator } \\
\text { load } \\
\text { resistance, } \mathrm{R}\end{array}$ & $5[\Omega]$ \\
\hline Torque of load, $\mathrm{T}_{\mathrm{c}}$ & $40[\mathrm{kNm}]$ & $\begin{array}{l}\text { Motor torque } \\
\text { constant, } \mathrm{kt}\end{array}$ & 0.82 \\
\hline
\end{tabular}




\begin{tabular}{|l|l|l|l|}
\hline $\begin{array}{l}\text { Inertia of sun gear, } \\
\mathrm{I}_{\mathrm{s}}\end{array}$ & $\begin{array}{l}0.39\left[\mathrm{~kg} \cdot \mathrm{m}^{2}\right. \\
]\end{array}$ & $\begin{array}{l}\text { Armature } \\
\text { inductance }\end{array}$ & $\begin{array}{l}1.5 \mathrm{e}-3[ \\
\mathrm{H}]\end{array}$ \\
\hline $\begin{array}{l}\text { Inertia of planet } \\
\text { gear, } \mathrm{I}_{\mathrm{p}}\end{array}$ & $\begin{array}{l}0.61\left[\mathrm{~kg} \cdot \mathrm{m}^{2}\right. \\
]\end{array}$ & $\begin{array}{l}\text { Friction } \\
\text { coefficient, } \mathrm{B}\end{array}$ & $9 \mathrm{e}-5$ \\
\hline $\begin{array}{l}\text { Inertia of planet } \\
\text { carrier, } \mathrm{I}_{\mathrm{c}}\end{array}$ & $3\left[\mathrm{~kg} \cdot \mathrm{m}^{2}\right]$ & $\begin{array}{l}\text { Back emf } \\
\text { constant, } \mathrm{kb}\end{array}$ & 0.82 \\
\hline $\begin{array}{l}\text { Average mesh } \\
\text { stiffness, } \mathrm{km}\end{array}$ & $1 \mathrm{e}+8[\mathrm{~N} / \mathrm{m}]$ & Flux, fi & $0.1[\mathrm{~Wb}]$ \\
\hline $\begin{array}{l}\text { Mesh angle of } \\
\text { gears, } \alpha\end{array}$ & $24.6[\mathrm{deg}]$ & & \\
\hline
\end{tabular}

Figure 3. Simulation Model Block diagram

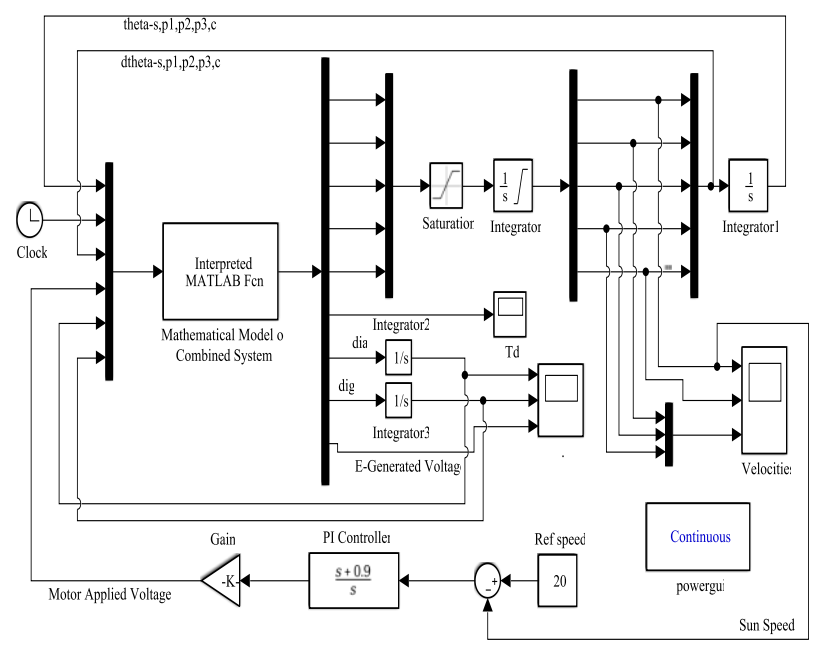

The input parameter to be defined for dynamic equation has been obtained from reference to the relevant literature [5], [7], [14]. The response has been obtained using all the parameters mentioned in Table 1. The parameters mentioned above are used in motor, planetary gear set and generator motion equations.

\section{Brief on Simulation block diagram}

The scope of interest lies in the analysis of the single stage three planet planetary gearset with the effect of transmission error using a mathematical model.

Figure 3, shows the Mathematical model hardcoded in MATLAB and Simulink used for simulating the transmission error with a gear defect amplitude. In the Simulink model an PI controller was introduced to enable an early settlement for the system. The stability of the system can be seen in a voltage and current signal, in this case the sun gear speed has been taken as the controller output and fed into the system as the variable input. The integral gain compensates the changing system dynamics and often aids the axis in rapidly changing command position or velocity. The Simulink model has been built with three components namely Motor, Single stage planetary gear set and Generator. These three components are important for power generation in a Wind turbine. The model is built in such a way that the motor drives the sun gear which drives the planets. The planets are fixed to the carrier, the planets in turn are supported by a ring carrier. The ring gear is a stationary element. The carrier which is being driven is driving the generator.

Table 2. Result table with parameter values achieved

\begin{tabular}{|c|c|c|}
\hline \multirow[t]{2}{*}{ Parameters } & \multicolumn{2}{|c|}{$\begin{array}{c}\text { Composite Error Function of Planets } \\
\qquad 1,2,3\end{array}$} \\
\hline & $\begin{array}{c}\text { Case-1 : When } \\
\begin{array}{c}\mathrm{e} 1=0, \mathrm{e} 2=0, \mathrm{e} 3 \\
=0\end{array}\end{array}$ & $\begin{array}{c}\text { Case-2 : When } \\
\mathrm{e} 1=0.0018, \mathrm{e} 2= \\
0, \mathrm{e} 3=0\end{array}$ \\
\hline $\begin{array}{l}\text { Motor Applied } \\
\text { Voltage, V }\end{array}$ & 137.81 & 133.45 \\
\hline
\end{tabular}

\begin{tabular}{|c|c|c|}
\hline Motor Current, dia & 313.70 & 194.72 \\
\hline $\begin{array}{l}\text { Motor Current, dia } \\
\text { THD \% }\end{array}$ & 133.28 & 922.21 \\
\hline $\begin{array}{l}\text { Motor Developed } \\
\text { Torque, TD }\end{array}$ & 257.24 & 159.67 \\
\hline Sun Speed, d $\theta$ s & 19.94 & 19.94 \\
\hline $\begin{array}{l}\text { Planet Speed 1,2,3, } \\
\mathrm{d} \theta \mathrm{p} 1, \mathrm{~d} \theta \mathrm{p} 2, \mathrm{~d} \theta \mathrm{p} 3\end{array}$ & 7.62 & 7.67 \\
\hline Carrier Speed, $d \theta c$ & 4.88 & 4.80 \\
\hline Generated Voltage, G & 877.59 & 867.59 \\
\hline Generator Current, dig & 29.25 & 28.92 \\
\hline $\begin{array}{l}\text { Generator Current, dig } \\
\text { THD\% }\end{array}$ & 83.02 & 522.20 \\
\hline
\end{tabular}

Figure 4. Comparing Current Signal and Voltage Signal of Motor, with error and without error



Figure 5. Comparing Current Signal and Voltage Signal of Generator, with error and without error
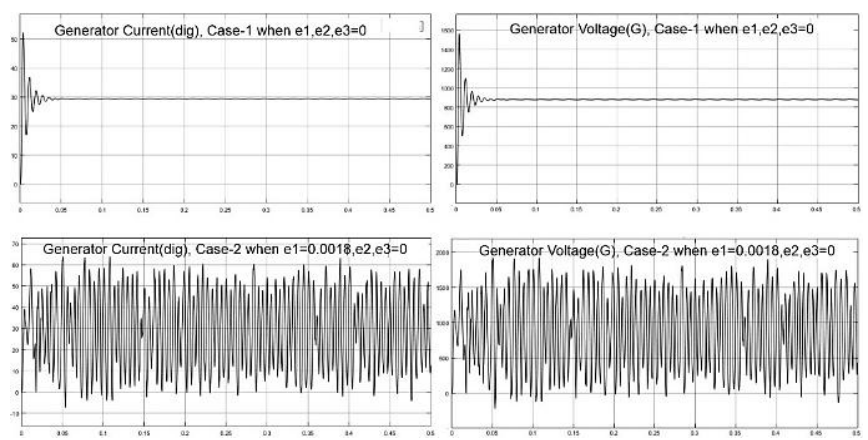

Table 2 presents overall result from the simulation study. The current profile carries a lot of information other than the current values. It carries the information relating to the vibration generated in the machine and its intensity. So the current profile analysis provides vibration details without dedication of costly sensor arrangements. In this research, Figure 4,5 shows the occurrence of the error in any form having a significant effect on current and voltage. Variations in the generator current pattern with respect to change in error condition are seen. Two error combination provides unique current profile patterns. Generator current profile is stable for both combinations of the error. But there are corresponding variations in the harmonics mixed in the pattern.

\section{CONCLUSION}

Transmission error is considered as the main contribution to noise and vibration in a gearbox. In this paper, a new approach of detecting the growth of gear defect via transmission error has been presented.

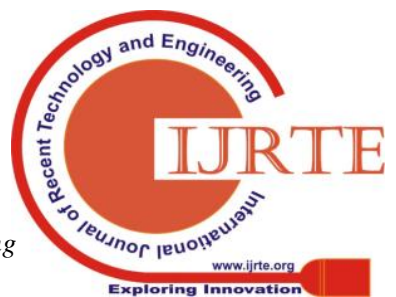


The single stage planetary gear set was modelled in MATLAB to make a study of the change in dynamic response while changing transmission error values. Normally the gear defects in planetary gearbox are distinguished and identified by tooth mesh frequencies(TMF). The vibration amplitude of a particular TMF of a planet gear has been given as transmission error in the model. The simulation model of a planetary gear set was interfaced with a Simulated Motor and Generator to enable a study of the change in the harmonics of current profile pattern. The key research related to finding out the change in electrical parameters of motor when there is mechanical fault in the gear set. In the simulation of planetary gear set and generator, any one of the planet is given an error and harmonic distortions in current and voltage are visualized. Ability to achieve the expected result when providing the real time wind turbine data in the place of error in simulation is available. This clearly indicates the response of the mathematical model responds to input errors and this model can offer help as a fault prediction tool in the early stages of gear defects.

\section{Acknowledgements}

The research work described in this paper was supported by Vestas Wind Systems A/S, Denmark.

\section{REFERENCES}

1. Cheng-Chi Huang., Mi-Ching Tsai., David G. Dorrell., Bor-Jeng Lin. Development of a Magnetic Planetary Gearbox. IEEE Transactions on Magnetics, Vol. 44, Issue 3, March 2008, p. 403-412.

2. Wei Li., Jingdong Sun., Jiapeng Yu. Analysis of dynamic characteristics of a multi-stage gear transmission system. Journal of Vibration and Control, First Published, February 2019.

3. Feng Li., Yumo Qin., Linshan Ge., Zhao Pang., Shaokang Liu., Donglong Lin. Influences of planetary gear parameters on the dynamic characteristics - a review. Journal of Vibroengineering, March 2015, Vol. 17, Issue 2, p. 574-586.

4. Shiwen He., Qingxuan Jia., Gang Chen., Hanxu Sun. Modeling and Dynamic Analysis of Planetary Gear Transmission Joints with Backlash. International Journal of Control and Automation, Vol. 8, No. 2 (2015), pp. 153-162.

5. F. Chaari., T. Fakhfakh., M. Haddar. Dynamic Analysis of a Planetary Gear Failure Caused by Tooth Pitting and Cracking. Journal of Failure Analysis and Prevention, Vol. 6(2) April 2006, p. 73-78.

6. Zijun Zhang., Anoop Verma, Student Member IEEE., Andrew Kusiak, Member IEEE. Fault Analysis and Condition Monitoring of the Wind Turbine Gearbox. IEEE Transactions on Energy Conversion, Vol. 27, No. 2, June 2012, p. 526-535.

7. Jianhua Cai., Xiaoqin Li. Gear fault diagnosis based on time-frequency domain de-noising using the generalized $\mathrm{S}$ transform. Journal of Vibration and Control, First Published, April 2017.

8. Lin Suo., Fei Liu., Guanghua Xu., Zhenyu Wang., Wenqiang Yan., Ailing Luo. Improved Park's Vector Method and its Application in Planetary Gearbox Fault Diagnosis. 2018 IEEE International Conference on Prognostics and Health Management (ICPHM).

9. Z.Daneshi-Far., H. Henao., G.A.Capolino. Planetary Gearbox Effects on Induction Machine in Wind Turbine : Modelling and Analysis. 2012 XXth International Conference on Electrical Machines, November 2012.

10. Yan-Feng CHEN., Xin-Yue WU., Jing JIN. Effect of Transmission Errors on the Dynamic Behavior of Planetary Gear Train. 2009 IEEE International Conference on Intelligent Computing and Intelligent Systems, December 2009.

11. Jungho Park., Jong Moon Ha., Hyunseok Oh., Byeng D. Youn., Joo-Ho Choi., Nam Ho Kim. Model-Based Fault Diagnosis of a Planetary Gear: A Novel Approach Using Transmission Error. IEEE Transactions on Reliability, Vol. 65, No. 4, December 2016, p. 1830-1841.



